\title{
Sampling Procedure for Establishing Criteria for Sea Urchin (Loxechinus albus) Proportion under the Legal Minimum Length of landings
}

\author{
Gustavo Di Giorgi ${ }^{1}$, Marvin Querales ${ }^{1}{ }^{\mathbb{D}}$, Javier E. Contreras-Reyes ${ }^{2, *} \mathbb{C}$, Danilo Pereira ${ }^{3}$ and \\ Carola Hernández-Santoro ${ }^{4}$ \\ 1 Instituto de Estadística, Facultad de Ciencias, Universidad de Valparaíso, Valparaíso 2360102, Chile; \\ gustavo.digiorgi@postgrado.uv.cl (G.D.G.); querales.marvin@gmail.com (M.Q.) \\ 2 Departamento de Estadística, Facultad de Ciencias, Universidad del Bío-Bío, Concepción 4081112, Chile \\ 3 Servicio Nacional de Pesca y Acuicultura (SERNAPESCA), Valparaíso 2340159, Chile; \\ dpereira@sernapesca.cl \\ 4 División de Investigación Pesquera, Instituto de Fomento Pesquero, Valparaíso 2361827, Chile; \\ carola.hernandez@ifop.cl \\ * Correspondence: jcontreras@ubiobio.cl; Tel.: +56-41-311-1199
}

Received: 31 December 2019; Accepted: 6 February 2020; Published: 9 February 2020

\begin{abstract}
Sea urchin (Loxechinus albus) is one of the most economically important species in the northeast of Chilean Patagonia, forming part of the highly diverse benthic community. This resource is being harvested under selective fishing pressure, which suppresses growth rates. In response, the National Standards Institute established Regulation 44 as a quality control measure, based on a sampling approach considering the percentage of sea urchin under the minimum legal size (UMLS) through an acceptance sampling plan. In 2019, the Chilean Undersecretary of Fisheries and Aquaculture (SUBPESCA), under Exempt Resolution No. 910, ruled that any vessel that landed 15\% with sea urchin of $6.5 \mathrm{~cm}$ UMLS of the total catch weight will be sanctioned. In this paper, a sampling design is presented to establish criteria regarding compliance with this provision. The plan provides a statistical methodology for the evaluation of the percentage of UMLS sea urchin, which corroborates and certifies the current legislation that sanctions and fines the capture of sea urchin that does not comply with UMLS values outlined in Regulation 44. Assuming a systematic sampling plan and under assumed UMLS values of $6.0,6.5$, and $7.0 \mathrm{~cm}$, it is determined that $15 \%$ of total landings (margin of tolerance) of sea urchin under $6.5 \mathrm{~cm}$ is the optimal level. Thus, a correct specification of the UMLS allows protecting the most vulnerable fraction of the population from overexploitation for growth.
\end{abstract}

Keywords: sea urchin; sampling procedure; minimum legal length; extraction; landing port; Chilean Patagonia

\section{Introduction}

Sea urchin (Loxechinus albus, Molina 1782) is an economically crucial species for the northeast of Chilean Patagonia, belonging to the highly diverse benthic community [1]. This species forms populations in areas of between 11,000 and 2,500,000 individuals, with densities of up to 11 individuals per square meter [2,3]. This fishery began in Chile in the 1940s, but steady growth did not occur until the mid-1970s [4]. The fishing pressure led to a crisis in 2001, which led to the establishment of a management plan that took effect in 2005. Since 2007, the management plan has been a fixed annual catch policy, set at 18,000 tonnes and a minimum size of capture of $6.0 \mathrm{~cm}$ in diameter [5]. A global catch quota was first established in 2011 based on an stock assessment that considered catch and effort information obtained directly from the landings [3]. 
According to the Chilean Undersecretary of Fisheries [6], sea urchin landings averaged 18,077 tons per year between 2010 and 2016. Moreover, it has been recorded that landings in Chile correspond to over $50 \%$ of global production of edible sea urchin [7]. The fleet operates over an indeterminate number of local patches along the intricate coastline of the sparsely populated fjords and channels of southern Chile. More specifically, almost $50 \%$ of the total landings come from the area around Chiloé Island $\left(41^{\circ} 47^{\prime} \mathrm{S}-43^{\circ} 28^{\prime} \mathrm{S}\right)$, which is separated from the mainland on its northern edge by Chacao Channel ( $\left.\sim 41^{\circ} 47^{\prime} \mathrm{S}\right)$ and to the south by Chonos Archipelago $\left(43^{\circ} 50^{\prime} \mathrm{S}-45^{\circ} 45^{\prime} \mathrm{S}\right)$ ([1,8,9]; see Figure 1).

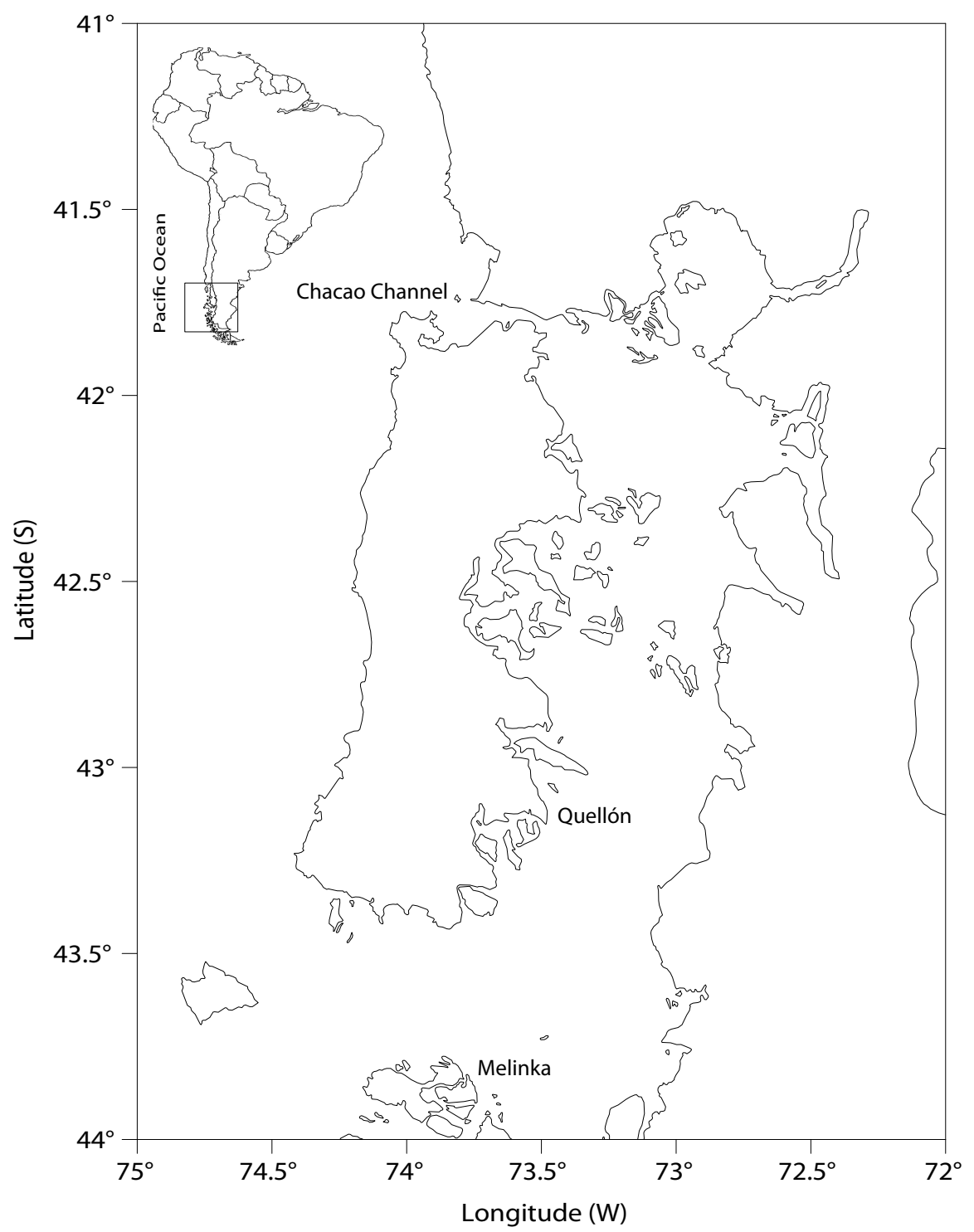

Figure 1. Study area restricted to catches of sea urchin of Chiloé Island $\left(41^{\circ} 47^{\prime} \mathrm{S}-43^{\circ} 28^{\prime} \mathrm{S}\right)$. The samples were taken from Melinka Port $\left(43^{\circ} 53^{\prime} \mathrm{S}, 73^{\circ} 44^{\prime} \mathrm{W}\right)$ and Quellón Port $\left(43^{\circ} 06^{\prime} \mathrm{S}, 73^{\circ} 36^{\prime} \mathrm{O}\right)$. As a reference, Chacao Channel $\left(\sim 41^{\circ} 47^{\prime} S\right)$ is indicated as the northern edge of Chiloé Island.

Studies by Balboa et al. [7] showed that sea urchin is being harvested under selective fishing pressure (and selective predation on females in Quellón [10]), which suppresses growth rates (see also [4,11]). Individual growth patterns and genetic effects on populations can lead to density-dependent and trophic consequences observed in benthic species and compensatory growth. It is also observed that the unusual growth pattern for larger individual urchins at a 5-15 $\mathrm{m}$ depth could be due to migration of adult urchins toward deeper habitats or a truncated size distribution due to the selective removal of adults by fishing activities [12]. Balboa et al. [7] stated that one effect 
of selective fishing pressure on sea urchin would be expressed by decreased average growth rates observed from changes in growth ring formation using mark-recapture methods.

In response, the National Standards Institute (INN) established Regulation 44 [13], defining quality control criteria using a sampling approach of the percentage of sea urchin under the minimum legal size (UMLS) [14] through an acceptance sampling plan. Under Exempt Resolution No. 910, SUBPESCA [15] ruled that any vessel that disembarks UMLS sea urchins in excess of $15 \%$ of catch weight will be sanctioned. For 2019, this resolution established the UMLS, with a capture tolerance margin of $15 \%$, at $7.0 \mathrm{~cm}$, in no case smaller than $6.0 \mathrm{~cm}$. The regulation was considered valid in the maritime areas of the Los Lagos and Aysén regions until 15 October 2019. However, after this resolution, the regulation [16] established through Exempt Resolution No. 2158 that vessels must not land more than $15 \%$ as a capture tolerance margin, but established UMLS at $6.5 \mathrm{~cm}$, while retaining the $6.0 \mathrm{~cm}$ threshold.

In this paper, a sampling plan design is presented to establish criteria regarding compliance with the provision. The present study was also conducted to deal with the confusion of criteria in size that have been assigned or misunderstood to define the fraction of UMLS sea urchins the fishery takes into account, an erroneous practice that persists. The insufficiency of statistically solid criteria for determining UMLS has motivated this study to define a sampling plan, which could find a sample size of sea urchin sample boxes at landing ports. This plan aims to provide a statistical methodology for the evaluation of the percentage of UMLS sea urchins to corroborate and certify the current legislation that sanctions and fines the capture of non-conforming individuals.

More specifically, it is intended to: (i) optimize the sample size of sea urchin sample boxes at landing ports; (ii) determine ports and their structural distribution size of sea urchins; (iii) determine receiver operating characteristic (ROC) curves from samples obtained in (ii); (iv) evaluate the conformity of urchin container boxes and evaluate the ROC curve for samples obtained in (ii), and with 6.0, 6.5 and $7.0 \mathrm{~cm}$ UMLS, according to a simulation scheme of 1000 sea urchin boxes; and (v) obtain conformity of sea urchin boxes from the sampling carried out by the National Fisheries Service [17].

\section{Methodology}

In this section, acceptance criteria and the systematic sampling method proposed by [18] and [19], respectively, are considered. It was assumed that two levels of quality were part of an acceptance sampling plan. The first was the level of quality desired by the customer (acceptable quality level $(\mathrm{AQL})$ ), where the producer's risk $(\alpha)$ was the possibility that the sampling plan did not verify an acceptable quantity in the lot and that, consequently, was rejected: a "type I" error. The risk was considered to be $10 \%$, specified as usual customer risk in Regulation 44 .

The other level of quality corresponded to the producer and was called RQL (rejectable quality level) or LTPD (lot tolerance percent defective). In this case, the producer corresponded to the owner responsible for the sea urchin landing. The LTPD was the worst level of quality the customer would tolerate. The probability of accepting a batch with LTPD quality was customer risk ( $\beta$ ), that is the "type II" error in the plan, whose legal representative was assumed to be the Chilean Undersecretary of Fisheries and Aquaculture. The entity established a tolerance range of $15 \%$ of landed catch weight, with specimens under the minimum extraction size of $6.5 \mathrm{~cm}$, and in no case smaller than $6 \mathrm{~cm}$. The risk of the producer $(\alpha)$ was the possibility that the sampling plan failed to verify an acceptable quantity in the lot and, consequently, was rejected: a "type I" error.

The operating characteristic (OC) curve described the degree to which a sampling plan allowed distinguishing between good and bad lots. It was desired to have a sampling plan that accepted $100 \%$ of the time the lots whose quality level was better than the AQL, but accepted lots with a quality level worse than the AQL $0 \%$ of the time. Figure 2 shows the relationship between the customer's quality level (AQL) and the producer's (LTPD or RQL) based on a plan of just one sampling. 


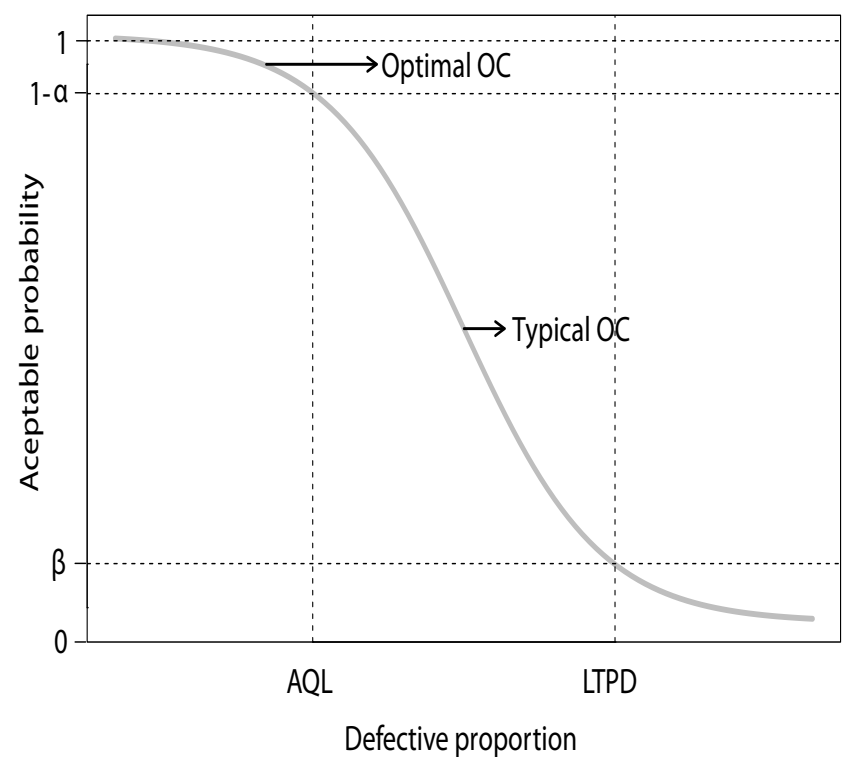

Figure 2. Typical operation curve for the relationship between acceptable quality level (AQL) and lot tolerance percent defective (LTPD), based on the procedure with one sampling. OC, operating characteristic.

Given that once sea urchins were landed, they were placed in container boxes, these boxes represented the sampling unit, and therefore, this sampling plan would show the " $n$ " number of sampling units (boxes) to be evaluated, the levels of acceptance " $c$ ", and the protocol to be followed for the evaluation of the sea urchins. Appendix A includes more details on the terminology and concepts. The methodological procedure consisted mainly of the following steps:

Step 1. Requires a statistical procedure that allows assessment of the level of risk of the vessel under evaluation and that provides a less subjective selection criterion. Considering the complexity of this feature, it will be assumed that the vessel has already been selected, and the possibility of a subsequent study focused on this step remains.

Step 2. After selecting the vessel, the number of sea urchin boxes after the landing is to be estimated. This estimate will provide the total of the units to be sampled and will depend on vessel capacity $(N)$.

Step 3. After estimating the number of boxes on the inspected vessel, the following procedure consists of evaluating how many boxes will be studied $(n)$.

Step 4. Once the size of the sample to be evaluated is known, it must be selected. To do so, a systematic sampling plan is carried out during landings and whose procedure is found in Appendix B.

Step 5. Once the value of nhas been obtained and the systematic sampling of the weight of the boxes carried out, the boxes are studied to see if they meet the acceptance criterion.

Steps 1-5 were based on the weight of the container. Because of the height-weight relationship, it was logical to assume a box with small urchins would have a different weight than a box with larger specimens. Therefore, a box weight cut-off point must exist that marked the boundary between boxes with a maximum of 15\% of UMLS sea urchin weight (called conforming) and boxes with a percentage of greater tolerance (called non-conforming). That is, boxes with a tolerance percentage in the capture of urchins greater than $15 \%$ would weigh more than the value considered as the cut-off point. To estimate that cut-off point, it was necessary to evaluate the origin of the sea urchin catch in the different landing ports. 
For this, the Fishery Development Institute's 2003-2017 [20] database of sea urchin weight and height samples was used (see also [2]). The data were registered in the Melinka and Quellón Ports of landings. With these data, it was possible to calculate volume $V(L)\left(\mathrm{cm}^{3}\right)$ :

$$
V(L)=\frac{4}{3} \pi\left(\frac{L}{2}\right)^{3}
$$

where $L$ is the diameter $(\mathrm{cm})$ of each sea urchin. This gave the dimensions of the urchin boxes, with which also their volume was obtained, at the time of landings in the respective landing ports.

Step 6. Having calculated the cut-off point by using the ROC curves and having classified boxes as conforming and non-conforming, if the number of the latter exceeded the maximum allowable value, the final procedure consisted of evaluating the tolerance percentage. This was with equation:

$$
\% \text { exceeds }=100 \times\left|0.15-\frac{\sum_{i=1}^{c} m_{i}}{\sum_{i=1}^{h} k_{i}}\right|
$$

where $m$ represents the weight of the non-conforming boxes, $c$ the total of non-conforming boxes, $k$ the weight of the boxes (conforming and non-conforming), $h$ the total number of boxes contained in the sample, and $|x|$ correspond to the absolute value of $x$.

The following scheme summarizes the previous steps:

Step 1. Vessel selection to be evaluated

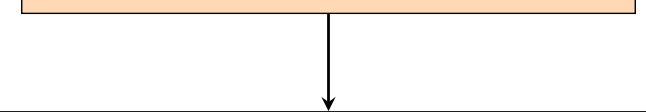

Step 2. Estimation of the number $N$ of sea urchin boxes after the landing

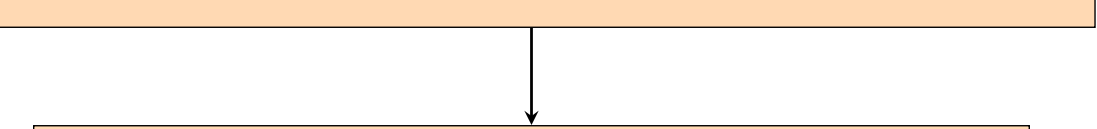

Step 3. Evaluation of the number $n$ of boxes that will be studied

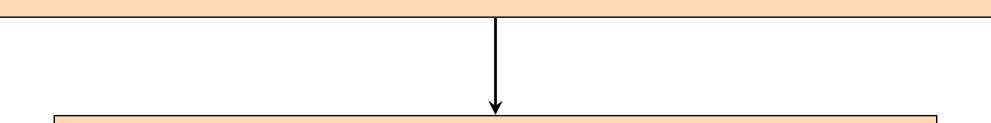

Step 4. Sample selection using systematic sampling plan

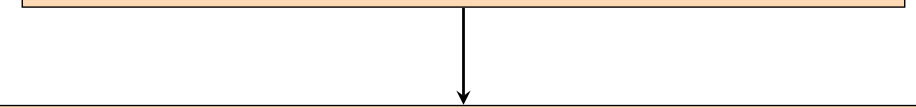

Step 5. Evaluation of each box in the selected sample by acceptation $(c)$ and rejection $(r)$ criteria

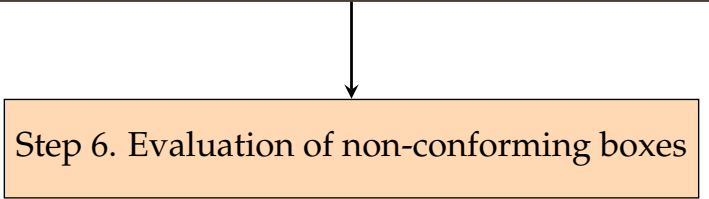

\section{Results}

The relationship between vessel capacity and approximate number of boxes is shown in Figure 3 . For this estimate, the original data provided by supervisor [17] were considered, regarding the dimensions of the container, as well as the average number of sea urchins that could fit, using information from Quellón and Melinka Ports. Only vessels with urchin landing capacities between 
0.1 and 60 tons were considered. The linear relationship covered practically all the data, so the linear equation could be considered a predictor of the number of boxes for a given landing.

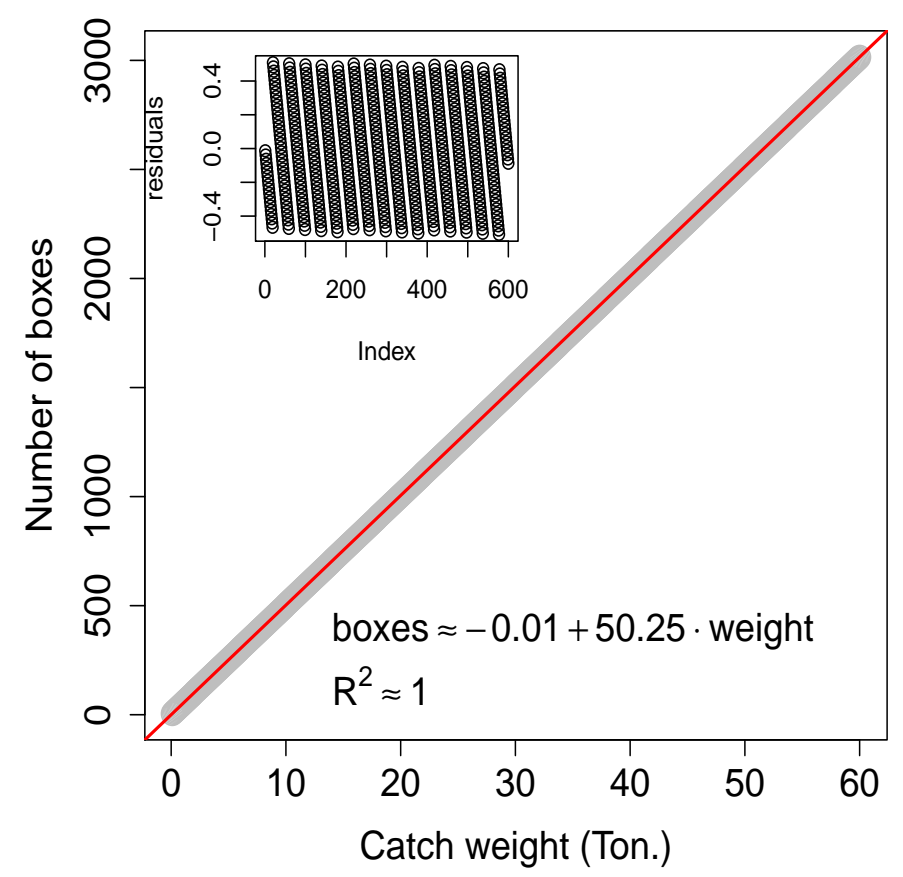

Figure 3. Unloaded catch ratio (ton) and number of boxes. Source: Chilean Undersecretary of Fisheries and Aquaculture (SUBPESCA, 2019b).

In accordance with Regulation 44, with $\mathrm{AQL}=10$ and considering a Level II inspection (recommended by the regulation), the data in Table 1 were obtained. This AQL value was considered because it was established in the regulation and because it remained below an RQL of 15. Given the difficulty to sample and select boxes during unloading, Table 1 was optimized to reduce the number of boxes to be evaluated and thus associated costs. The comparison was made using the operating characteristic (OC) curves, average total inspection (ATI), and average outgoing quality level (AOQL) curves. The results are presented in the Supplementary Material, and updated values appear in Table 1.

Table 1. Total units containing the sea urchins shown in Regulation 44 and optimization of the numbers of sea urchin boxes for sampling (modified version of the criteria shown in Regulation 44). For the samples obtained by Regulation 44, the sample size $(n)$ and criteria of acceptance $(c)$ and rejection $(r)$ are according to the total units containing the sea urchins $(N$, urchin boxes that disembark a boat or total boxes available in a processing plant).

\begin{tabular}{ccccccc}
\hline & \multicolumn{3}{c}{ Regulation $\mathbf{4 4}$} & \multicolumn{3}{c}{ Optimization } \\
\cline { 2 - 7 } $\boldsymbol{N}$ & $\boldsymbol{n}$ & $\boldsymbol{c}$ & $\boldsymbol{r}$ & $\boldsymbol{n}$ & $\boldsymbol{c}$ & $\boldsymbol{r}$ \\
\hline$\leq 25$ & 5 & 1 & 2 & 5 & 1 & 2 \\
$26-50$ & 8 & 2 & 3 & 8 & 2 & 3 \\
$51-90$ & 13 & 3 & 4 & 10 & 2 & 3 \\
$91-150$ & 20 & 5 & 6 & 17 & 4 & 5 \\
$151-280$ & 32 & 7 & 8 & 28 & 6 & 7 \\
$281-500$ & 50 & 10 & 11 & 40 & 8 & 9 \\
$501-1200$ & 80 & 14 & 15 & 65 & 11 & 12 \\
$\geq 1201$ & 125 & 21 & 22 & 105 & 17 & 18 \\
\hline
\end{tabular}

The dataset was divided into three subsets: Melinka Port $\left(43^{\circ} 53^{\prime} \mathrm{S}, 73^{\circ} 44^{\prime} \mathrm{W}\right)$, Quellón Port $\left(43^{\circ} 06^{\prime} \mathrm{S}, 73^{\circ} 36^{\prime} \mathrm{O}\right)$, and the entire study area $\left(41^{\circ} 47^{\prime} \mathrm{S}-43^{\circ} 28^{\prime} \mathrm{S}\right)$ excluding Melinka Port (see Figure 1) (see also the clustering criteria in [21]). This latter subset was necessary because the Melinka data 
showed a homogeneous size structure of sea urchin landings, while size structures from the other ports were variable and heterogeneous, given catch origins. Table 2 contains descriptive statistics of these three data subsets, and the distributions and boxplots of sea urchin lengths at the three landing ports appear in Figure 4. Table 2 and Figure 4 illustrate the presence of atypical observations producing differences between the sea urchin size averages in the three data subsets considered. We observed significant differences between Quellón and the other sub-zones, because the Quellón's size structure is variable and heterogeneous. On the another hand, Melinka and complete data excluding Melinka Port showed a homogeneous size structure of sea urchin landings.

a)

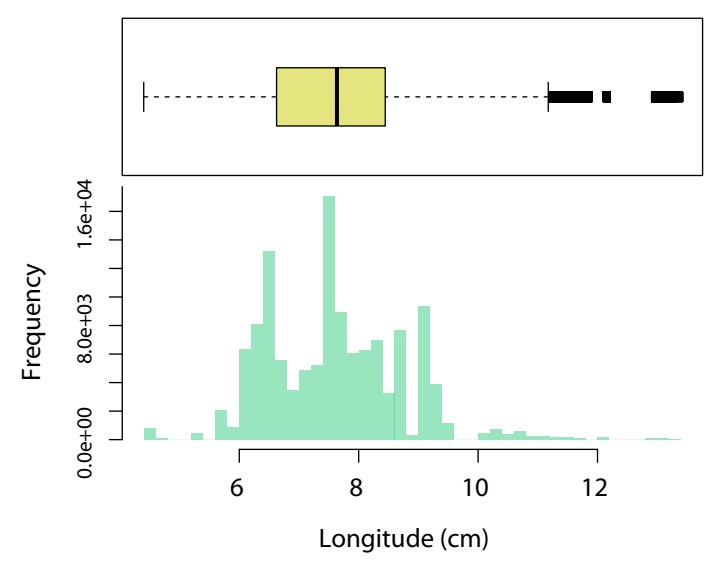

b)

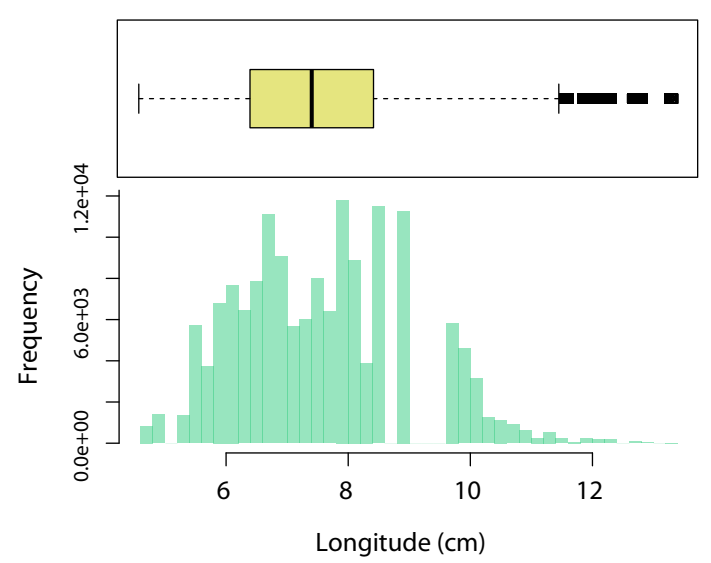

c)

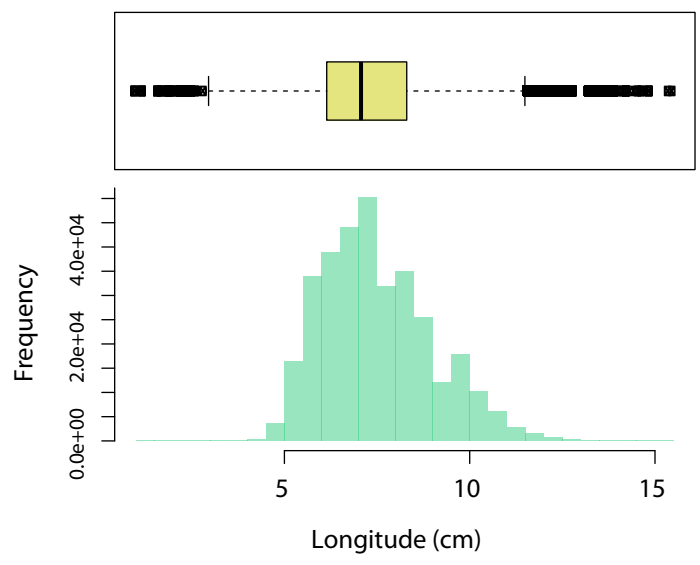

Figure 4. Distribution and boxplots of structures of sea urchin sizes in the three data subsets considered: Melinka Port (a), Quellón Port (b), and complete data excluding Melinka Port (c).

A programming code was then implemented with $\mathrm{R}$ software [22] to generate an analysis model of the box weight and to categorize boxes as conforming or non-conforming (see Appendix $C$ ) through ROC curve analysis (see the Supplementary Material).

Simulations were conducted with 1000 sea urchin boxes using IFOP's size data, where the volume of each individual $\left(\mathrm{cm}^{3}\right.$, obtained randomly and without replacement) was compared with the box volume of Melinka urchins until it no longer met the condition that the volume of individuals was less than the volume of the container. 
Using R software allowed obtaining the weight and height vectors of sea urchins in each box, in the form of the percentage of urchins under $6.5 \mathrm{~cm}$ and a tolerance percentage of $15 \%$. Knowing the weight percentage of each box provided by UMLS sea urchin, each of the boxes in the simulation was classified as "conforming" or "non-conforming" if it fulfilled this condition established in Resolution No. 2158 [16]. With these data, the ROC curve was constructed, allowing obtaining the cut-off point and its respective sensitivity and specificity values.

Table 2. Summary of the main statistics of sea urchin sizes $(\mathrm{cm})$ in the three data subsets considered.

\begin{tabular}{cccc}
\hline Statistic & Melinka Port & Quellón Port & Studied Area Excluding Melinka Port \\
\hline$n$ & 125,579 & 154,624 & 331,531 \\
Minimum & 4.4 & 4.7 & 1.4 \\
$1^{\text {st }}$ quartile & 6.6 & 6.5 & 6.4 \\
Median & 7.6 & 7.5 & 7.3 \\
Mean & 7.65 & 7.62 & 7.56 \\
$3^{\text {rd }}$ quartile & 8.4 & 8.5 & 8.5 \\
Maximum & 13.3 & 13.4 & 15.5 \\
\hline
\end{tabular}

In Melinka, Quellón, and Castro Ports, SERNAPESCA obtained a pilot sample by weighing 145 boxes. Urchins in these boxes were evaluated and the UMLS percentage calculated, classifying the boxes as conforming or non-conforming.

\subsection{Melinka Port}

The classification of conforming and non-conforming boxes was made considering the weight obtained as a cut-off point in the simulations with Melinka data $(28,146.5 \mathrm{~g})$. A container box was considered conforming (conformity in Table 3 ) if the weight percentage contributed by sea urchins under the legal minimum size did not exceed the acceptable quality level (AQL), established at $15 \%$. A container box was considered non-conforming (non-conforming in Table 3) if the weight percentage contributed by sea urchins under the legal minimum size exceeded the established AQL of $15 \%$ or, indistinctly, individuals smaller than $6.0 \mathrm{~cm}$. The results are shown in Table 3 .

Table 3. Evaluation of the conformity of boxes, for Melinka Port, Quellón Port, and the complete data excluding Melinka Port, according to the simulation of 1000 boxes with urchin, considering different under the minimum legal size (UMLS) values.

\begin{tabular}{lcccc}
\hline Landing Ports' UMLS & $\mathbf{5 . 5} \mathbf{~ c m}$ & $\mathbf{6 . 0} \mathbf{~ c m}$ & $\mathbf{6 . 5} \mathbf{~ c m}$ & $\mathbf{7 . 0} \mathbf{~ c m}$ \\
\hline Melinka & & & & \\
\hline Conformity & - & - & 239 & - \\
Non-conformity & - & - & 761 & - \\
Cut-off point & - & - & $28,146.5$ & - \\
Specificity & - & - & 65.1 & - \\
Sensitivity & - & - & 63.2 & - \\
\hline Quellón & & & & \\
\hline Conformity & 351 & 640 & 4 & - \\
Non-conformity & 649 & 360 & 996 & 1000 \\
Cut-off point & 295,770 & 298,265 & - & - \\
Specificity & 53.3 & 52.9 & - & - \\
Sensitivity & 59.0 & 53.6 & - & - \\
\hline Studied area excluding & & & & \\
Melinka Port & & & & \\
\hline Conformity & 54 & 306 & 1 & - \\
Non-conformity & 946 & 694 & 999 & 1000 \\
Cut-off point & 363,175 & 355,105 & - & - \\
Specificity & 62.9 & 58.5 & - & - \\
Sensitivity & 62.9 & 61.8 & - & - \\
\hline
\end{tabular}


Figure 5 a shows the results with MLS $=6.5 \mathrm{~cm}$. It was observed that between the two groups, a difference in weight existed that could be discriminated according to a cut-off point generated in the ROC curve (Figure 5b). An area under the curve of $68 \%$ was observed, and the cut-off point obtained was $28,146.5 \mathrm{~g}$ with a specificity of $65.1 \%$ and a sensitivity of $63.2 \%$.
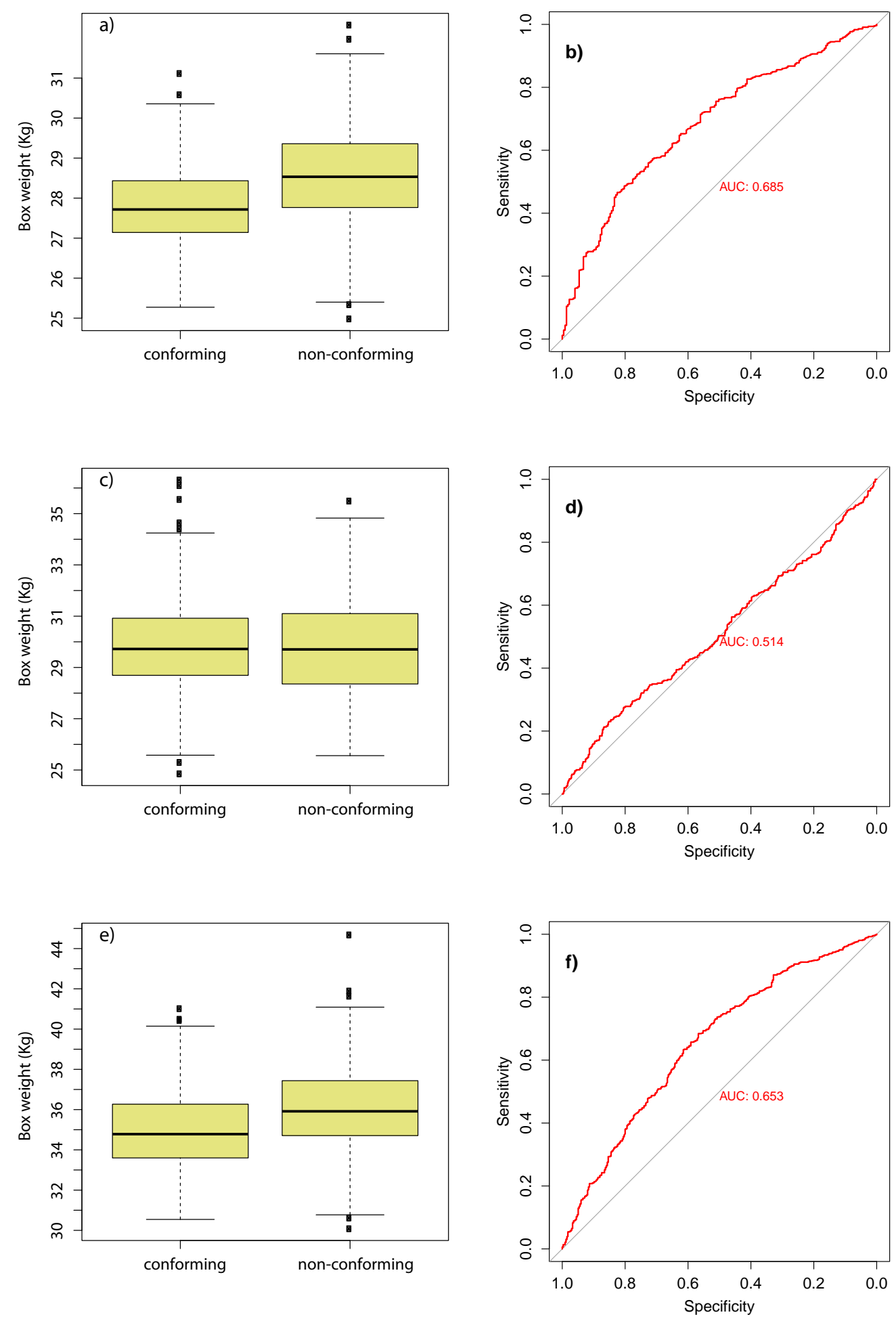

Figure 5. Conformity assessment of the container boxes (left column) and evaluation of the ROC curve (right column) in the ports of $(\mathbf{a}, \mathbf{b})$ Melinka $($ UMLS $=6.5 \mathrm{~cm}),(\mathbf{c}, \mathbf{d})$ Quellón (UMLS $=6.0 \mathrm{~cm})$, and $(e, f)$ complete area excluding Melinka $(U M L S=6.0 \mathrm{~cm})$, according to the simulation of 1000 boxes. 


\subsection{Quellón Port and Study Area Excluding Melinka}

For Quellón Port and the complete data excluding Melinka Port, the simulation study considering MLS of $6.5 \mathrm{~cm}$ did not generate enough conforming boxes. Hence, it was not possible to continue ROC curve analysis (Table 3, Panels C-F of Figure 5).

In Table 4, the results of conformity, sampled by SERNAPESCA during August 2018, are presented. They showed that the criterion of the cut-off point favored specificity, according to the conforming boxes, but not the non-conforming ones. It should be noted that the pilot sample was problematic to take because of the little time left at the end of the 2018 season. Still, in the pilot sample, the percentage in excess of the tolerance percentage was calculated according to Step 6, giving $12.43 \%$.

Table 4. Compliance results in the pilot sample, developed by SERNAPESCA during August 2018, in Melinka, Quellón and Castro ports.

\begin{tabular}{lcc}
\hline & \multicolumn{2}{c}{ Evaluation of Boxes Considering the Cut-Off Point } \\
\hline Evaluation & Conformity & Non- Conformity \\
\hline Conformity & 112 & 0 \\
Non-conformity & 33 & 2 \\
Total & 145 & 2 \\
\hline
\end{tabular}

The results in the simulated samples appear in Figure 6, which shows how the percentages of excess tolerance of UMLS catch were distributed in the different datasets. Boxplots illustrate the presence of atypical observations producing differences between the sea urchin box weights in the three data subsets considered. The reported weight averages were 20.1, 16.5, and $42.6 \mathrm{~kg}$ for the study area excluding Melinka Port and Melinka and Quellón Ports, respectively; showing significant differences between Quellón and the other sub-zones. This was because Quellón's weight distribution was variable and heterogeneous, given catch origins, while Melinka data showed a homogeneous weight distribution of sea urchin landings.

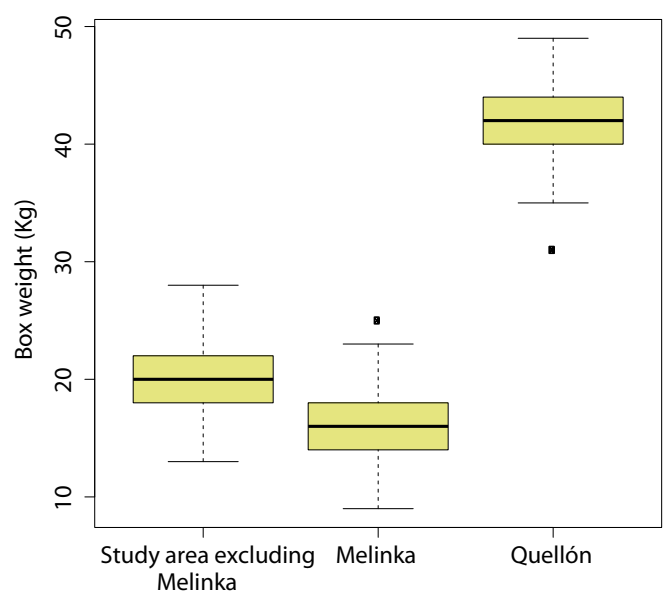

Figure 6. Percentages of UMLS weight difference in the datasets, according to the simulation (Figure 5).

\section{Discussion and Conclusions}

In this work, a statistical sampling plan was developed to determine the percentage of sea urchins in catches. Under UMLS values assumed as $6.0,6.5$, and $7.0 \mathrm{~cm}$, according to $[15,16]$, it was determined that $15 \%$ of the total landing (margin of tolerance) of sea urchins under $6.5 \mathrm{~cm}$ was the optimum level, assuming a systematic sampling plan proposed by [18] and [19]. Moreover, the result obtained was consistent for Melinka Port, with the provisions of Regulation 44 [13] to monitor compliance with Exempt Resolution No. 2158 [16]. 
In Quellón Port, the non-differentiation of a weight cut-off point defined between conforming and non-conforming sea urchin boxes resulted from the highly heterogeneous nature of the size distribution of sea urchins in this area. This could be related to the intensive diving effort needed to capture urchins over time and the different environmental conditions, complicating the analysis for establishing a cut-off point [6]. Another point in particular is the UMLS, which probably did not reflect the diverse sea urchin weights and sizes in this area. This means that was feasible to work with the results from Melinka Port as a point of reference for Aysén Region and the city of Castro.

The sampling method based on individual weights did not necessarily assume a linear weight-age relationship, such as in the von Bertalanffy growth models used for fish catches based on the age-length relationship (see, e.g., [23,24]). This was because some old and young sea urchins with equal lengths could have similar weight. In addition, the boxes' weight was highly influenced by the size structure of sea urchin stocks. Therefore, the proposed approach could lead to bias especially when natural stocks in Quellón are intensively fished [12] or size structures are highly shifted [25]. In the last case, a size structure analysis should be performed to ensure the validity of the proposed method in future applications.

The proposed scheme had the following advantages: (i) low cost, even with planning and administering sampling plans, as only part of the catch was inspected; (ii) few inspection staff, thereby simplifying coordination and reducing room for manipulation; (iii) reduced inspection error, waiting time, and monotony; and (iv) less damage for the resources because of sparse handling.

To validate the proposal and evaluate the incorporation of conditions that have not yet been considered, the proposed sampling procedure based on quality could be applied in a pilot study during the next harvest season (from October 2019 to October 2020). Importantly, the procedure in this paper could be used for a dataset corresponding to a particular year, that is if each size frame of sea urchins were updated annually, the sampling method could be used every year or from the oldest year to the current one.

On the other hand, one of the most important direct consequences of correct UMLS specification [14] is that it allows the most vulnerable fraction of the population to be protected from overexploitation [26]. Since resource assessment models consider the size of the resource (see, e.g., [5]), the estimation of UMLS eventually affects the conservation and evaluation of the resource in the sense of population abundance, and therefore the size of the resource population. Thus, faulty UMLS specification can become a critical error source or create bias in abundance parameters.

Finally, it is worth noting that other factors could be included in the sampling plan, such as the size-feeding relationship [27]; seasonality, gonadal development and reproductive status [10]; feeding differences and growth [12]; abundance [5]; life history parameters [11]; other environmental factors; and the plan's possible effects on re-population techniques [28]. In addition, the detection of the selective fishing pressure effects allow studying the life history parameters of exploited sea urchins under more natural conditions [12].

Supplementary Materials: The following are available at http:/ / www.mdpi.com/2077-1312/8/2/102/s1.

Author Contributions: G.D.G., M.Q., and J.E.C.-R wrote the paper and contributed analysis tools; D.P. and C.H.-S. contributed reagents/materials/tools; G.D.G., M.Q., and J.E.C.-R. conceived of, designed, and performed the experiments and analyzed the data. All authors read and agreed to the published version of the manuscript.

Acknowledgments: The authors thank Nancy Barahona and Claudio Vicencio (IFOP) for providing sea urchin length-size data used in this work. Contreras-Reyes's research was partially supported by FONDECYT (Chile) grant No. 11190116. We are sincerely grateful to the three anonymous reviewers for their comments and suggestions, which greatly improved an early version of this manuscript.

Conflicts of Interest: The authors declare no conflict of interest.

\section{Appendix A. Glossary}

Acceptance criterion (c): Represents the maximum number of container boxes considered "non-conforming" that sample " $n$ " should have to consider lot " $N$ " acceptable and free of sanction. 
Criterion of rejection $(r)$ : Represents the minimum number of container boxes considered non-conforming that the sample " $n$ " should have to consider the lot " $N$ " as not acceptable and proceed to the establishment of the corresponding penalty or fine.

Operating characteristic (OC) curves: Present the discriminatory power of an acceptance sampling plan. The graph shows the probability of accepting a lot versus the defective fraction. Represents the complement of the AOQL and ATI curves.

Average total inspection (ATI): These graphs show the relationship between the quality of the incoming material and the number of elements that must be inspected, assuming that the rejected lots are $100 \%$ inspected and a rectification inspection of defect elements is carried out, just as the AOQL curves allow comparisons between sampling plans. The curves are constructed following a Poisson distribution.

Sample $(n)$ : Constitutes the number of boxes containing urchins that will be evaluated during the inspection.

Acceptable quality level (AQL): Quality level that represents the highest acceptable defect rate of the process of a producer. For this sampling program, it was considered as $10 \%$, with the value specified as the customer's usual risk as defined in Regulation 44.

Rejectable quality level (RQL or LTPD): Represents the highest defective rate the examiner is willing to tolerate in an individual lot. For this sampling program, it was set at $15 \%$, since this represents the maximum weight percentage of sea urchins under the legal minimum size that can be tolerated. The RQL must be greater than the AQL.

Average outgoing quality level (AOQ): AOQ graphs represent the relationship between the quality of the incoming and outgoing material. The average outgoing quality limit (AOQL) represents the maximum percentage of defectives in the outgoing product, and its graphs allow comparison between sampling plans. Generally, the curves are constructed following a Poisson distribution.

Customer risk $(\beta)$ : The controlling entity is considered a customer, and its risk is translated as the probability of accepting a bad catch, defined as a percentage of small sizes greater than the critical percentage established.

Producer risk $(\alpha)$ : The owner who has made a certain catch is considered a producer. His/her risk is considered as the probability of rejecting a good catch in the sense that it contains a percentage of small sizes lower than the critical percentage established.

Lot size $(N)$ : Represents the total of urchin container boxes a vessel generates after landing in a port.

\section{Appendix B. Procedure to Select the Containers to Be Evaluated in Sample $n$, Following Systematic Sampling}

Systematic sampling is applicable when the elements of the population for which the sampling is carried out are ordered. This procedure is based on taking samples in a direct and orderly manner from a deterministic rule, hence systematic. Specifically, from a single unit that is first selected, the rest of the units in the sample are automatically determined by applying a systematic selection rule to that unit. Under this procedure, for example, every 20th name on a list can be selected, every 12th house on one side of a street, every 50th piece of an assembly line, and so on.

Here, we consider the simplest systematic sampling design, called systematic uniform step sampling $k$ [19]. Obtaining a systematic size sample $n$ of a population of $N$ elements is achieved by adhering to the following procedure:

1. Obtain an ordered list of $\mathrm{N}$ elements of the population.

2. Determine sample size $n$.

3. Define the size of the systematic jump $k$ given by $k=N / n$.

4. Choose a random number $\delta$ between one and $k$ ( $\delta$ : random start). This number allows obtaining the first sample unit. 
5. From position $\delta$, jumping $k$ units will get to the second unit of the sample $u \delta+k$, and this way jumping from $k$ in $k$ units, the rest of the sample will be formed by units $u \delta+2 k, u \delta+3 k, \ldots, u \delta+$ $(n-1) k$.

Example A1. We considered a population of 8000 sampling units (number of boxes containing sea urchins) belonging to a certain area of those studied and from which we intended to extract a systematic sample of 105 units (Table 1). The procedure is as follows:

1. Define the size of the systematic jump: this is calculated by $k=N / n=8000 / 105=76$.

2. Select a random number between one and 76 (for example, 35).

3. Select the remaining elements of the sample, $35,35+76=111,111+76=187,187+76=263,263+$ $76=339, \ldots, 7939$. The latter value was estimated using arithmetic progression:

$$
a_{n}=a_{1}+k(n-1)=35+50(160-1)=7939 .
$$

Actually, under systematic sampling, we classified the population units in $n$ zones or rows of size $k$, numbered them from left to right beginning with the first unit of the first row and passing to the first unit of the next row once the previous row has been exhausted. Once numbered, we could express the $N=n k$ units in the following way:

$$
\left(\begin{array}{c}
i \\
1 \\
2 \\
3 \\
\vdots \\
i \\
\vdots \\
n
\end{array}\right) \rightarrow\left(\begin{array}{c}
1 \\
u_{1} \\
u_{k+1} \\
u_{2 k+1} \\
\vdots \\
u_{(i-1) k+1} \\
\vdots \\
u_{(n-1) k+1}
\end{array}\right) \rightarrow\left(\begin{array}{c}
2 \\
u_{2} \\
u_{k+2} \\
u_{2 k+2} \\
\vdots \\
u_{(i-1) k+2} \\
\vdots \\
u_{(n-1) k+2}
\end{array}\right) \rightarrow \ldots \rightarrow\left(\begin{array}{c}
j \\
u_{j} \\
u_{k+j} \\
u_{2 k+j} \\
\vdots \\
u_{(i-1) k+j} \\
\vdots \\
u_{(n-1) k+j}
\end{array}\right) \rightarrow \ldots \rightarrow\left(\begin{array}{c}
k \\
u_{k} \\
u_{k+k} \\
u_{2 k+k} \\
\vdots \\
u_{(i-1) k+k} \\
\vdots \\
u_{(n-1) k+k}
\end{array}\right)
$$

With these specifications, the sample space consisted of the following possible samples $k$ :

$$
\begin{aligned}
\left(S_{1}\right) & =\left\{u_{1}, u_{1+k}, u_{1+2 k}, \ldots, u_{1+(n-1) k}\right\} \\
\left(S_{2}\right) & =\left\{u_{2}, u_{2+k}, u_{2+2 k}, \ldots, u_{2+(n-1) k}\right\} \\
\vdots & \\
\left(S_{k}\right) & =\left\{u_{k}, u_{k+k}, u_{k+2 k}, \ldots, u_{k+(n-1) k}\right\} .
\end{aligned}
$$

Each of these samples had probability equal to $1 / k=n / N$ to be selected. The first and second order inclusion probabilities corresponding to this sample design are:

$$
\pi_{i}=\sum_{s \in S} \mathbb{P}\left[u_{i} \in s\right]=\frac{1}{k}=\frac{n}{N}, \quad i=1,2, \ldots, N
$$

and

$$
\pi_{i j}= \begin{cases}\frac{1}{k} \mathbb{P}\left[\left(u_{i}, u_{j}\right) \in s\right], & \text { if }\left(u_{i}, u_{j}\right) \in s, i \neq j, \\ 0, & \text { if }\left(u_{i}, u_{j}\right) \notin s, i \neq j ;\end{cases}
$$

respectively.

Unlike those that can occur in random sampling, no large sequence of elements was left without representation. Consequently, if the elements considered in the order in which they appeared on the 
list had to form groups or zones of similar elements with respect to the characteristic that was studied, systematic sampling could be more representative than simple random sampling.

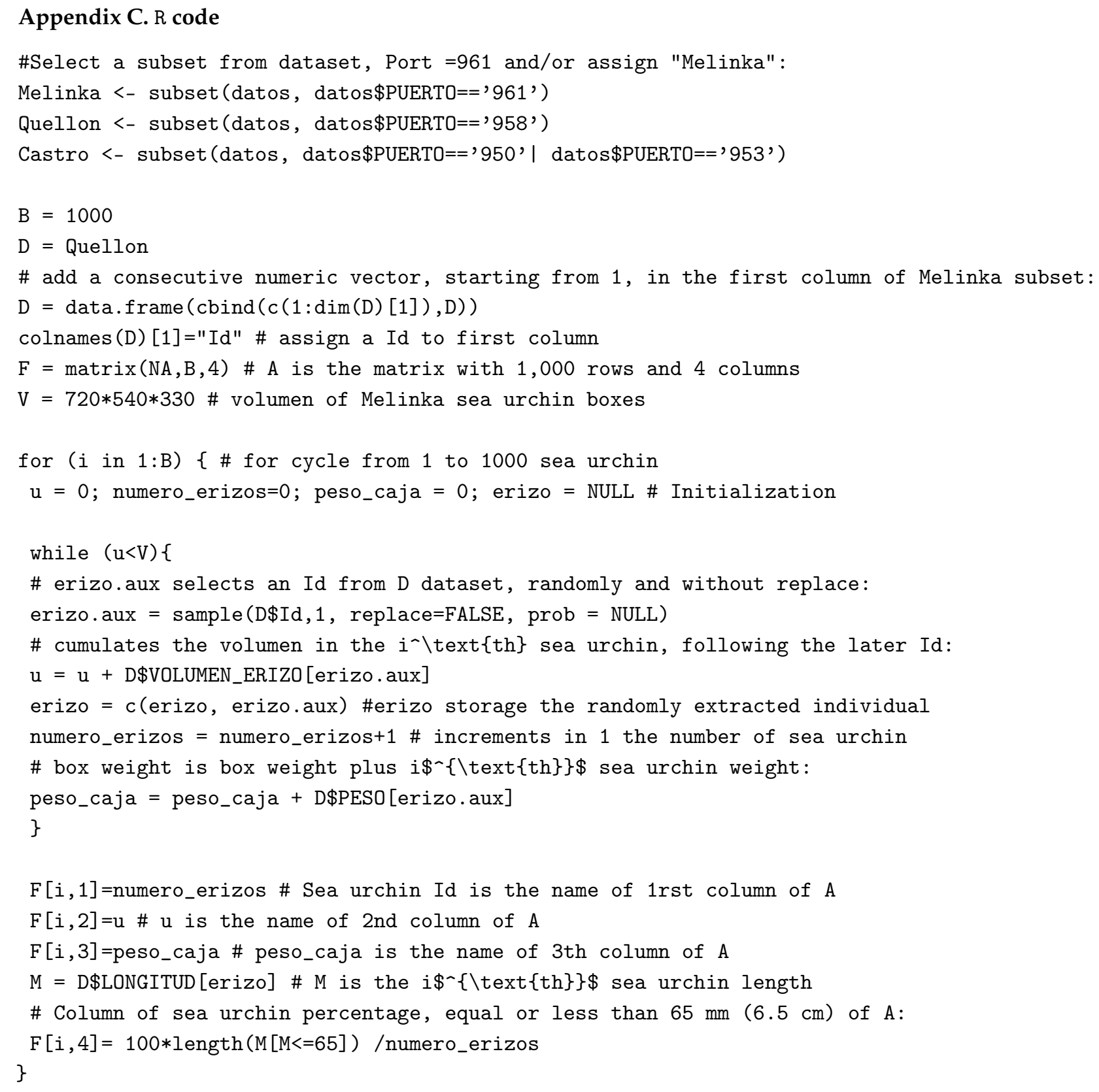

\section{References}

1. Contreras, C.; Niklitschek, E.; Molinet, C.; Díaz, P.; Díaz, M. Fishery-induced reductions in density and size truncation of sea urchin Loxechinus albus affects diversity and species composition in benthic communities. Estuar. Coast. Shelf Sci. 2019, 219, 409-419. [CrossRef]

2. Barahona, N.; Araya, P.; Muñoz, G.; Vicencio, C.; Olguín, A.; Cavieres, J.; Canales, C.; Subiabre, D.; Techeira, C.; Hurtado, C. Programa de Seguimiento de las Pesquerías Bentónicas; Instituto de Fomento Pesquero: Valparaíso, Indiana, 2016; p. 2015. Available online: https://www.ifop.cl/wp-content/contenidos/uploads / RepositorioIfop/InformeFinal/P-583011.pdf (accessed on 15 May 2019). 
3. Molinet, C.; Barahona, N.; Díaz, M.; Díaz, P.A.; Millanao, M.O.; Araya, P.; Subiabre, D.; Niklitschek, E.J. Using Drift Video Transects and Maximum Likelihood Geostatistics for Quantifying and Monitoring Exploited Subpopulations of Loxechinus albus at a Mesoscale. Mar. Coast. Fish. Dyn. Manag. Ecosyst. Sci. 2016, 8, 70-80. [CrossRef]

4. McClanahan, T.; Castilla, J.C. Fisheries Management: Progress Towards Sustainability; Blackwell Publishing: Oxford, UK, 2007.

5. Roa-Ureta, R.H.; Molinet, C.; Barahona, N.; Araya, P. Hierarchical statistical framework to combine generalized depletion models and biomass dynamic models in the stock assessment of the Chilean sea urchin (Loxechinus albus) fishery. Fish. Res. 2015, 171, 59-67. [CrossRef]

6. SUBPESCA. Cuota de Captura y Talla Mínima de Extracción de erizo. Plan de Manejo Zona Contigua X-XI Regiones; Comité Científico Técnico Bentónico; INFORME: Valparaíso, Chile, March 2017. Available online: http:/ / www.subpesca.cl/portal/616/articles-95941_documento.pdf (accessed on 15 August 2018).

7. Balboa, C.; Molinet, C.; Barahona, N.; Díaz, P.A.; Subiabre, D.; Gebauer, P. Using growth ring formation to study growth patterns of exploited sea urchin (Loxechinus albus) populations. Fish. Res. 2018, 201, 88-97. [CrossRef]

8. Kino, S. Juvenile ecology of the sea urchin Loxechinus albus in Chiloé Island, Chile. Aqua Sci. 2009, 57, 567-577.

9. Kino, S. Transplantation of the sea urchin Loxechinus albus in Chiloé Island, Chile. Aqua Sci. 2010, 58, 55-63.

10. Molinet, C.; Moreno, C.A.; Niklitschek, E.; Matamala, M.; Neculman, M.; Arévalo, A.; Codjambassis, J.; Díaz, P.A.; Díaz, M. Reproduction of the sea urchin Loxechinus albus across a bathymetric gradient in the Chilean Inland Sea. Rev. Biol. Mar. Oceanogr. 2012, 47, 257-272. [CrossRef]

11. Narvaez, C.A.; Johnson, L.E.; Sainte-Marie, B. Growth bands are an unreliable indicator of sea urchin age: evidence from the laboratory and the literature. Limn. Oceanogr. Meth. 2016, 14, 527-541. [CrossRef]

12. Molinet, C.; Balboa, C.A.; Moreno, C.A.; Díaz, M.; Gebauer, P.; Niklitschek, E.J.; Barahona, N. Variability in the growth patterns of Loxechinus albus along a bathymetric gradient associated with a fishing ground. Bull. Mar. Sci. 2013, 89, 699-716. [CrossRef]

13. INN. Procedimientos de muestreo para inspección de atributos - Planes de muestreo indexados por nivel de calidad aceptable $(A Q L)$ para la inspección lote por lote; Instituto Nacional de Normalización, Norma Chilena Oficial, Santiago, Chile: 2007.

14. Cabrera, R.; Valero-Franco, C.; Piniella, F.; Díaz, C.; Gómez-Cama, M.C.; Soriguer, M.C.; Hernando, J.A. A software tool for monitoring legal minimum length of landings: Case study of a fishery in southern Spain. Mar. Pol. 2012, 36, 895-902. [CrossRef]

15. SUBPESCA. Establece talla mínima de extracción para el recurso erizo y margen de tolerancia en área y período que indica; Resolución Extenta Nro 910; Subsecretaría de Pesca y Acuicultura: Valparaíso, Chile, 15 March 2019. Available online: http://www.subpesca.cl/portal/615/articles-103618_documento.pdf (accessed on 15 May 2019).

16. SUBPESCA. Establece margen de tolerancia bajo la talla mínima de extracción para el recurso erizo en área y periódo que indica; Resolución Extenta Nro 2158; Subsecretaría de Pesca y Acuicultura: Valparaíso, Chile, 11 July 2019. Available online: http://www.subpesca.cl/portal/615/articles-104538_documento.pdf (accessed on 15 August 2019).

17. SERNAPESCA. Servicio Nacional de Pesca y Acuicultura, Valparaíso, Chile, 2019. Available online: http:/ / www.sernapesca.cl/ (accessed on 15 August 2018).

18. Grant, E.L.; Leavenworth, R.S. Statistical Quality Control, 6th ed.; McGraw-Hill: New York, NY, USA, 1988.

19. Hildebrandt, G. Sampling plans on microbiological criteria. In Encyclopedia of Food Microbiology, 2nd ed.; Elsevier: San Diego, CA, USA, 2014; Volume 3.

20. IFOP. Instituto de Fomento Pesquero, Valparaíso, Chile, 2017. Available online: https://www.ifop.cl/en/ (accessed on 15 August 2018).

21. Molinet, C.; Barahona, N.; Yannicelli, B.; González, J.; Arevalo, A.; Rosales, S. Statistical and empirical identification of multispecies harvesting zones to improve monitoring, assessment, and management of benthic fisheries in Southern Chile. Bull. Mar. Sci. 2011, 897, 351-375. [CrossRef]

22. R Core Team. R: A Language and Environment for Statistical Computing; R Foundation for Statistical Computing: Vienna, Austria, 2018; ISBN 3-900051-07-0. Available online: http:/ /www.R-project.org/ (accessed on 15 August 2018). 
23. Quintero, F.O.L.; Contreras-Reyes, J.E.; Wiff, R.; Arellano-Valle, R.B. Flexible Bayesian analysis of the von Bertalanffy growth function with the use of a log-skew-t distribution. Fish. Bull. 2017, 115, 13-26. [CrossRef]

24. Contreras-Reyes, J.E.; Quintero, F.O.L.; Yáñez, A.A. Towards age determination of Southern King crab (Lithodes Santolla) off Southern Chile using flexible mixture modeling. J. Mar. Sci. Eng. 2018, 6, 157. [CrossRef]

25. Contreras-Reyes, J.E.; Cortés, D.D. Bounds on Rényi and Shannon Entropies for Finite Mixtures of Multivariate Skew-Normal Distributions: Application to Swordfish (Xiphias gladius Linnaeus). Entropy 2016, 18, 382. [CrossRef]

26. Walker, K.; Aranis, A.; Contreras-Reyes, J.E. Possible Criterion to Estimate the Juvenile Reference Length of Common Sardine (Strangomera bentincki) off Central-Southern Chile. J. Mar. Sci. Eng. 2018, 6, 82. [CrossRef]

27. Olave, S.; Bustos, E.; Lawrence, J.M.; Cárcamo, P. The effect of size and diet on gonad production by the Chilean sea urchin Loxechinus albus. J. World Aquac. Soc. 2001, 32, 210-214. [CrossRef]

28. Espinoza, R.; Arriagada, S. Repoblamiento de Loxechinus albus: Manual de producción de semilla con fines de repoblamiento; Project HUAM AQ08I1024; FONDEF, Universidad de Los Lagos: Puerto Montt, Chile, 2017.

(C) 2020 by the authors. Licensee MDPI, Basel, Switzerland. This article is an open access article distributed under the terms and conditions of the Creative Commons Attribution (CC BY) license (http:// creativecommons.org/licenses/by/4.0/). 